\title{
THE INFLUENCE OF HARDARIAN GLAND REMOVAL AND FUR LIPID REMOVAL ON HEAT LOSS AND WATER FLUX TO AND FROM THE SKIN OF MUSKRATS, ONDOTRA ZIBETHICUS'
}

\author{
HENRY JAMES HARLOW \\ Department of Zoology and Physiology; University of Wyoming, Laramie, Wyoming 82071 \\ (Accepted 10/28/83)
}

\begin{abstract}
The Hardarian gland (an apocrine organ located behind the eye) was removed from one group of muskrats. Another group of muskrats was anesthetized and shampooed. The fur of shampooed and Hardarianectomized muskrats did not appear to repel water as effectively as sham control animals. Both shampooed and Hardarianectomized muskrats had higher rates of heat loss while submerged in a $4 \mathrm{C}$ water bath than sham control animals. The magnitude of heat loss was less for the Hardarianectomized muskrats. Hardarianectomized and shampooed muskrats had elevated rates of evaporative water loss with an estimated cutaneous water loss of $52 \%$ and $66 \%$ of total evaporative water loss for Hardarianectomized and shampooed muskrats compared with $41 \%$ for control animals. Coating the fur of muskrats with mineral oil tended to retard evaporative water loss. It appears that the Hardarian gland is an effective source of lipids which may be spread onto the fur from the nasal duct by both self and communal grooming. This lipid coat appears to help retard heat loss as well as water flux to and from the skin.
\end{abstract}

\section{INTRODUCTION}

The muskrat, Ondotra zibethicus, is a semiaquatic mammal which is broadly distributed from the tropics to the arctic and consequently endures extreme thermal environments (MacArthur and Aleksiuk 1979). For example, during winter they forage in ice-covered water (Johansen 1962; Miller and Irving 1967), and on hot summer days their activity is primarily restricted to the lodge (Lay 1945) in which temperatures often exceed the upper critical temperature of the muskrat (Hart 1962; MacArthur and Aleksiuk 1979). The importance of lipids in enhancing the quality of fur as a protective barrier in cold as well as hot environments has not been fully explored in any mammalian species. Lipids in the fur may be instrumental in retaining the vital air layer on which muskrats de-

\footnotetext{
I extend my appreciation to my wife and son for their help in collecting muskrats in mosquito-clouded marshes and to Lisa Walters for her help in feeding and maintaining these animals in captivity. I thank Stan Lindstedt for his suggestions on portions of this manuscript. This work was supported in part by a University of Wyoming grant-in-aid and basic research grant.
}

Physiol. Zool. 57(3):349-356. 1984.

(C) 1984 by The University of Chicago. All rights reserved. 0031-935X/84/5703-8355\$02.00 pend for a considerable amount of their insulation (Johansen 1962). In addition, during heat stress, lipids may retard evaporative water loss through the skin (Quay 1965; Nicolaides 1974). In view of the importance of lipids in maintenance of a nonwettable fur as a means of providing buoyancy (Johansen 1962), cold resistance, and possibly heat tolerance, an additional source of lipids to augment the sebaceous gland secretions would be advantageous to the muskrat.

One source of lipids demonstrated to have thermoregulatory importance is secretions of the Hardarian gland (Thiessen and Kittrell 1980). These glands are large, lobular tubuloalveolar apocrine organs situated within the orbital cavity directly behind the eye (Graffin 1942). The Hardarian glands in many rodents are rich in porphyrins (Kennedy 1970) and lipids (Cohn 1955; Hais, Strych, and Chemlar 1968) which are secreted into the anterior corner of the eye as well as the external nares (Davis 1929; Venable and Grafflin 1970). Thiessen and Kittrell (1980) have demonstrated that the gerbil (Meriones unguiculatus) spreads these lipids over the entire body coat during autogrooming in a way analogous to the use of preen glands of certain birds, thereby providing insu- 
lation against wetness and cold. The Hardarian gland, therefore, may serve an important adaptive function for the muskrat by enhancing fur lipid content and potentially increasing the barrier against water penetration to and from the animal.

It is the purpose of this study to determine the effect of total lipid removal and Hardarian gland removal on: (1) water penetration into the fur and resultant heat loss while the animal is submerged in cold water, (2) thermal conductance of the fur in cold air, and (3) cutaneous evaporative water loss in a hot air environment. In addition, this study will investigate the effect of oiling the fur on the rate of cutaneous water loss.

\section{MATERIAL AND METHODS}

Muskrats were live trapped during June and July 1982 in southeastern Wyoming $\left(42^{\circ} 00^{\prime} \mathrm{N} 105^{\circ} 20^{\prime} \mathrm{W}\right)$ at approximately 2,200-m elevation. Muskrats were housed either individually in $1 \times 1-\mathrm{m}$ metal cages, with ample fresh water for drinking and swimming, or in groups of three in $1 \times 3$ $\mathrm{m}$ stainless steel cages with continuously circulating water for both drinking and swimming. All animals were maintained on a natural photoperiod and provided fresh vegetables and fruit ad lib. along with occasional fish and frogs. Only adult muskrats of similar body mass (909 $\mathrm{g} \pm 44$ $\mathrm{SD})$ were used in the following studies.

SURGICAL MANIPULATION

Hardarianectomy was performed on six muskrats under ketamine anesthesia (1.5 $\mathrm{mg} / \mathrm{kg}$ ) injected intramuscularly. A $0.5-\mathrm{cm}$ incision was made in the nictitating membrane at the anterior corner of the eye with a no. 20 scalpel. The superior lobe of the gland was grasped with two serrated forceps and carefully pulled out through the incision, to maintain the gland intact during its removal. After the entire gland was exposed, its anteromedial attachment in the orbital cavity was cut. The procedure was then repeated on the other side. Sham operations were performed on seven muskrats by making a cut in the nictitating membrane and inserting the forceps to touch the Hardarian gland but not remove it.
EXPERIMENT 1: EFFECT OF HARDARIANECTOMY AND SHAMPOOING ON HEAT LOSS

The body temperatures of animals in all three groups (control, Hardarianectomized, and shampooed) were monitored prior to, during, and after forced submergence in cold water.

Body temperatures of sham control animals were measured with a thermocouple inserted $4 \mathrm{~cm}$ into the rectum and were continuously recorded on a Sargent-Welch model SRG-2 recorder. Each animal was placed in a $17 \times 17 \times 30-\mathrm{cm}$ wire cage for $10 \mathrm{~min}$ in order to obtain deep core temperature. The cage containing the muskrat was then lowered into a circulating water bath maintained at $4 \mathrm{C}( \pm 0.2)$ so that only the nose and mouth of the muskrat protruded from the water. Body temperature was monitored for the 10 min each muskrat was submerged and for an additional 10 min after emergence.

Six muskrats were lightly anesthetized at $0400 \mathrm{MST}$, shampooed twice with a mild baby shampoo, rinsed, blow dried, and allowed to recover $5-6 \mathrm{~h}$ prior to submergence as previously described. Six Hardarianectomized muskrats were also monitored during presubmergence, submergence, and postemergence in a manner similar to the other two groups and at approximately the same time of day.

An analysis of variance followed by a Student-Neuman-Keuls test for interaction was performed on values representing the total temperature drop by muskrats caused by cold exposure (Sokal and Rohlf 1969). An $F$-statistic comparing the sum square error was calculated to determine whether regression lines representing the rate of body temperature change were different among the three groups (Netter and Wasserman 1974).

\section{EXPERIMENT 2: EFFECT OF HARDARIANECTOMY ON THERMAL CONDUCTANCE}

Six control and six Hardarianectomized muskrats were placed into a $14 \times 14 \times$ $25-\mathrm{cm}$ hardware cloth cage which slid into an airtight temperature control chamber. Ambient air temperature inside the chamber was recorded simultaneously with body temperature. Rate of air flowing into the chamber at $10 \mathrm{C}( \pm 0.2)$ was determined with a hot wire anemometer. The excur- 
rent air was channeled to a Beckman F-3 paramagnetic oxygen analyzer to determine oxygen content. Oxygen consumption rates for muskrats were determined from formula 10 of Depocas and Hart (1957). Thermal conductance was then approximated from the formula $C=M /\left(T_{\mathrm{b}}\right.$, $-T_{\mathrm{a}}$ ), where $M=$ oxygen consumption, $T_{\mathrm{b}}=$ body temperature, and $T_{\mathrm{a}}=$ ambient temperature. A pooled $t$-test was used to test for significant differences between the means of these two groups.

EXPERIMENT 3: EFFECT OF HARDARIANECTOMY AND SHAMPOOENG ON EVAPORATIVE WATER LOSS

Six individuals from each group were placed into a hardware cloth cage suspended over a tray containing mineral oil and were maintained at $36 \mathrm{C}( \pm 0.2)$ in a temperature control chamber. Air previously scrubbed of water was pumped into the chamber. The excurrent air was monitored for water content by an EG\&G Dew Point Hygrometer and then for oxygen content as previously described. Both evaporative water loss and oxygen consumption were measured on muskrats in the chamber for $30 \mathrm{~min}$. In order to establish cutaneous evaporative water loss, certain estimations had to be made. Because the percent oxygen extraction in mammals is roughly constant (inspired air is $21 \% \mathrm{O}_{2}$ and expired air is $16 \% \mathrm{O}_{2}$ ), the minute volume of the muskrat was estimated at 20 times its oxygen consumption. The temperature of the expired air was measured directly with a copper-constantan thermocouple and Thermometrics V$1 \mathrm{~B}$ micro-voltmeter to be about $33 \mathrm{C}$. From the estimated volume of expired air, the amount of water lost was calculated, assuming that this air was saturated with moisture. Cutaneous evaporation was, therefore, obtained by subtracting the calculated respiratory evaporation from the total measured evaporation. An analysis of variance followed by a Student-Neuman-Keuls test for interaction was performed on evaporative water loss and oxygen consumption of these three groups.

EXPERIMENT 4: EFFECT OF OILING THE FUR ON EVAPORATIVE WATER LOSS

Five muskrats were individually placed into the temperature control chamber at
$36 \mathrm{C}$ for $30 \mathrm{~min}$ to determine their baseline water loss rates. Each animal was then removed from the chamber and allowed to rest for $4 \mathrm{~h}$. At the end of this time, muskrats were firmly held while mineral oil was rubbed into their fur. After an additional $1 \mathrm{~h}$ of rest, muskrats were returned to the $36 \mathrm{C}$ chamber to provide a second 30-min reading of evaporative water loss. A paired $t$-test was performed on these data to determine whether oiling significantly changed an individual's evaporative water loss.

\section{RESULTS}

The adult muskrat has large J-shaped Hardarian glands weighing an average of $0.79 \mathrm{~g}$ and measuring about $29 \mathrm{~mm}$ in length and $10 \mathrm{~mm}$ in width (fig. 1).

The fur of muskrats, $2 \mathrm{wk}$ after surgical removal of these glands, had a dull appearance and lacked the uniform fluffiness typical of the sham control muskrats. When dipped in and out of the water, fur of the shampooed and Hardarianectomized muskrats became wet down to the skin and compressed into a dense mat. On the other hand, fur of the control muskrats remained dry at the skin and appeared light and erect after emergence from the water (fig. 2).

The body temperature of sham control muskrats that were submerged in a $4 \mathrm{C}$ water bath for 10 min dropped $4 \mathrm{C}$ over $20 \mathrm{~min}$, and they exhibited no ill effects as a result of the cold exposure. However, shampooed muskrats under similar test conditions had significantly higher rates of heat loss $(P<.005)$ than controls; the average body temperature decrease after 20 min was $14.3 \mathrm{C}$. Hardarianectomized muskrats also had a significantly greater heat loss than the control group $(P<.05)$, but body temperature decreased ( $7.4 \mathrm{C}$ ) less than in the shampooed group. Both Hardarianectomized and shampooed muskrats had a temporary impairment of locomotor ability after the 10-min forced submergence in cold water. The control and Hardarianectomized muskrats did not demonstrate a decline in body temperature until after $6 \mathrm{~min}$ of submergence, while the shampooed group became hypothermic only after $4 \mathrm{~min}$ in cold water. The regression lines representing the body tempera- 


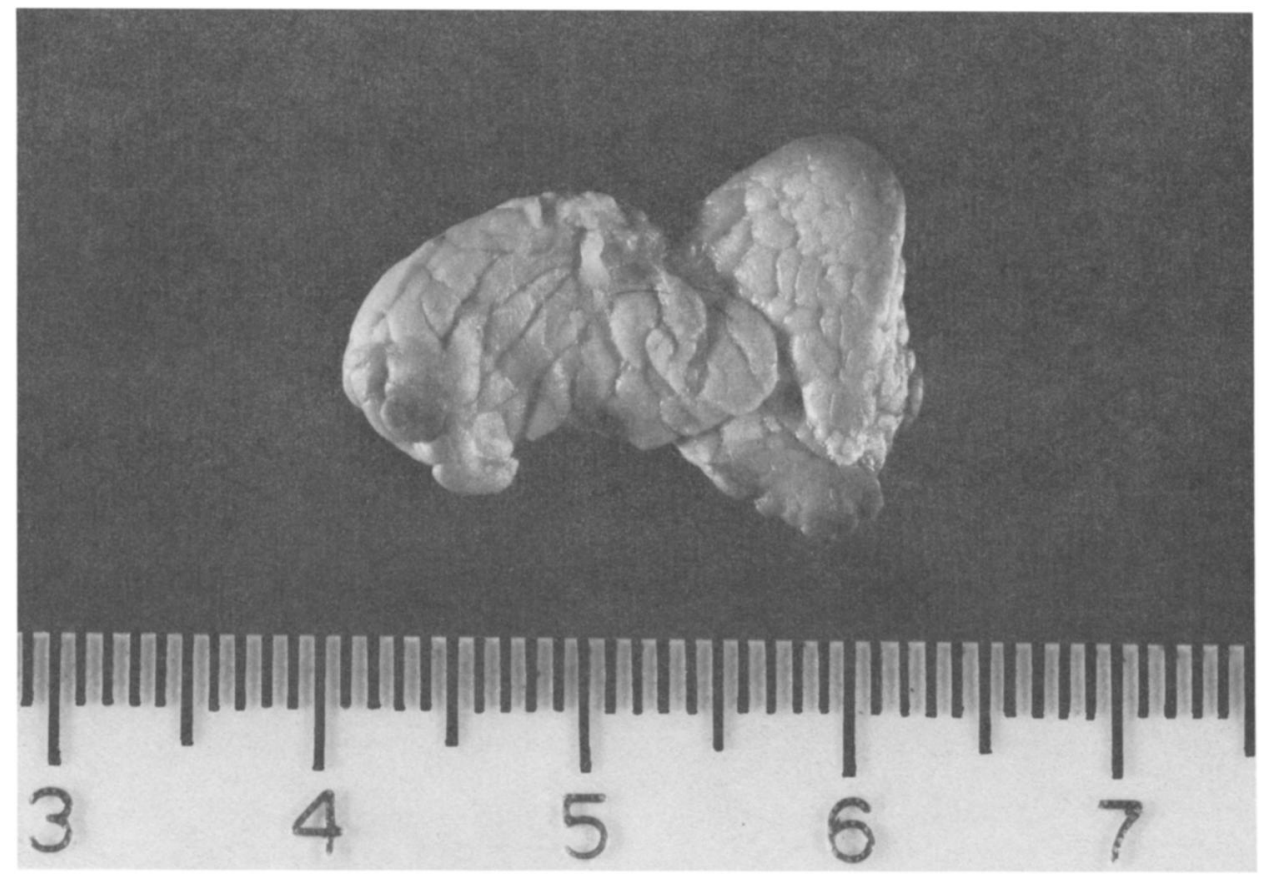

FIG. 1.-A Hardarian gland removed intact from the postorbital sinus of a muskrat

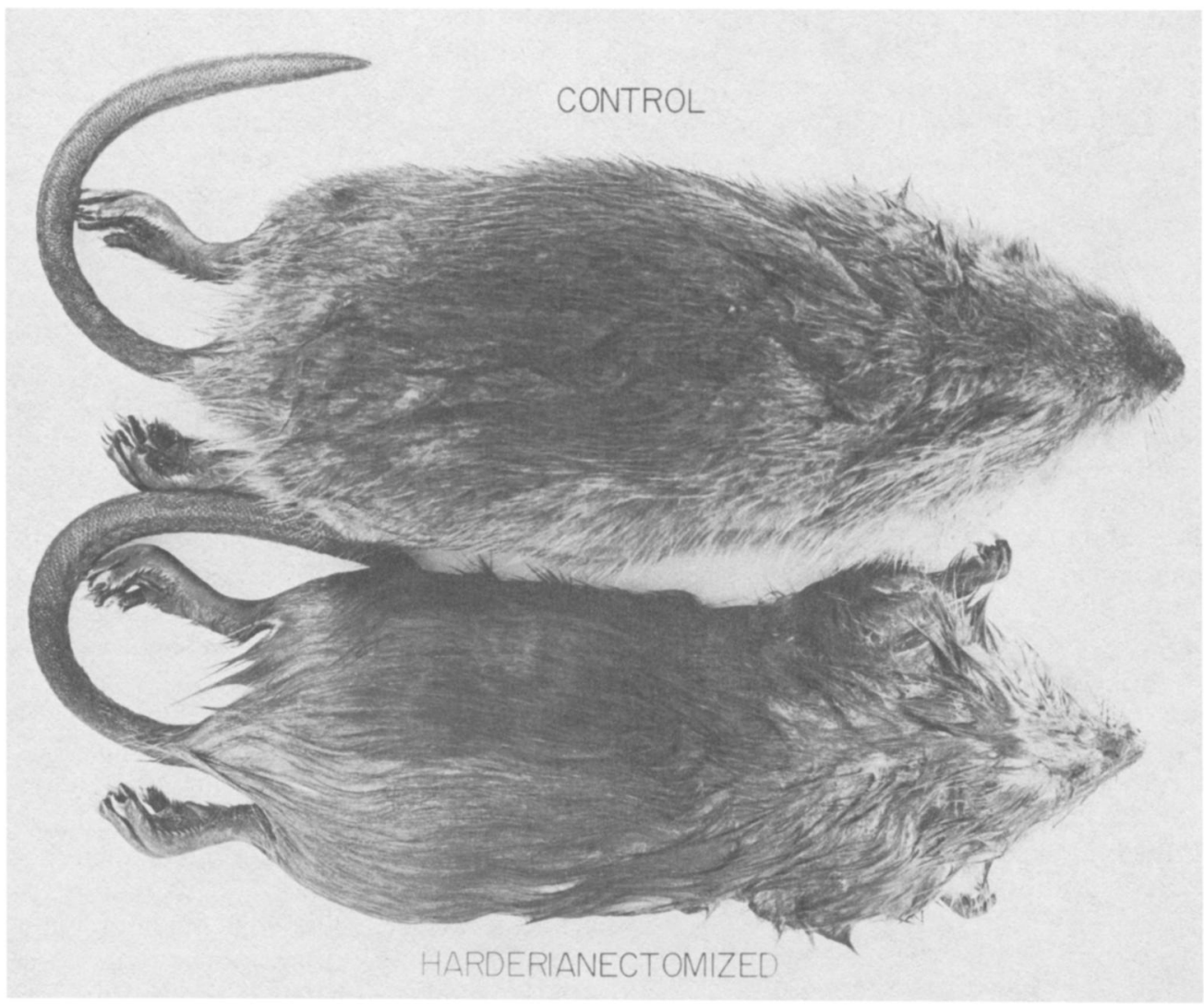

FIG. 2.-Comparison of pelage wetness of an anesthetized control and Hardarianectomized muskrat briefly submerged underwater. 
ture drop during the interval between 6 and 20 min postsubmergence were significantly different for Hardarianectomized $(P<.05)$ and shampooed $(P<.005)$ groups compared with the control group (fig. 3). The slope of the body temperature curve of the Hardarianectomized group, however, was not as great $(P<.10)$ as that of the shampooed group (fig. 3).

Oxygen consumption of control $(0.862$ $\left.\mathrm{cm}^{3} / \mathrm{g} \cdot \mathrm{h}\right)$ and Hardarianectomized $(0.851$ $\left.\mathrm{cm}^{3} / \mathrm{g} \cdot \mathrm{h}\right)$ muskrats was not significantly different at an air temperature of $6 \mathrm{C}$. In addition, thermal conductances of control $\left(0.034 \mathrm{~cm}^{3} \cdot \mathrm{g}^{1} \cdot \mathrm{h}^{-1} \mathrm{C}^{-1}\right)$ and Hardarianectomized $\left(0.035 \mathrm{~cm}^{3} \cdot \mathrm{g}^{-1} \cdot \mathrm{h}^{-1} \mathrm{C}^{-1}\right)$ muskrats were also not significantly different at this ambient temperature.

Shampooing significantly increased the extent of evaporative water loss by muskrats in a hot environment $(P<.05)$. Hardarianectomized muskrats had evaporative water loss rates which were also greater $(P<.10)$ than sham control muskrats (fig. $4)$. In addition, when muskrats were covered with mineral oil, their evaporative water loss rates in a hot environment were decreased $(P<.10)$ (fig. 5).

\section{DISCUSSION}

Several functions have been hypothesized for the Hardarian gland which in-

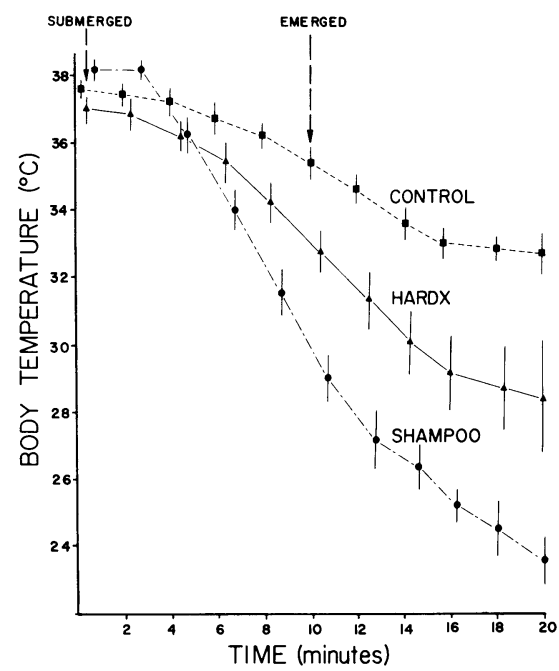

Fig. 3.- Mean body temperatures $\left({ }^{\circ} \mathrm{C}\right)$ of seven control, six Hardarianectomized, and six shampooed muskrats during $10 \mathrm{~min}$ of forced submergence in $4 \mathrm{C}$ water followed by $10 \mathrm{~min}$ postemergence at room temperature $(22 \mathrm{C})$. Vertical lines represent $\pm 2 \mathrm{SEM}$.

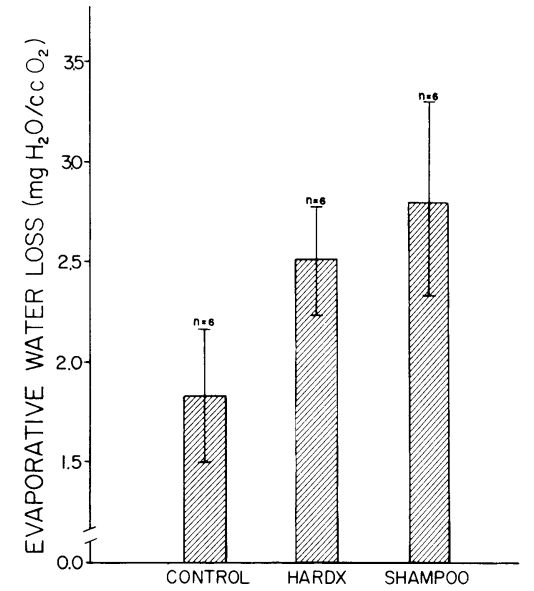

FIG. 4.-Mean evaporative water loss $\left(\mathrm{mg} / \mathrm{cm}^{3} \mathrm{O}_{2}\right)$ of six control, six Hardarianectomized, and six shampooed muskrats at an ambient temperature of $36 \mathrm{C}$. Vertical bars represent \pm 2 SEM.

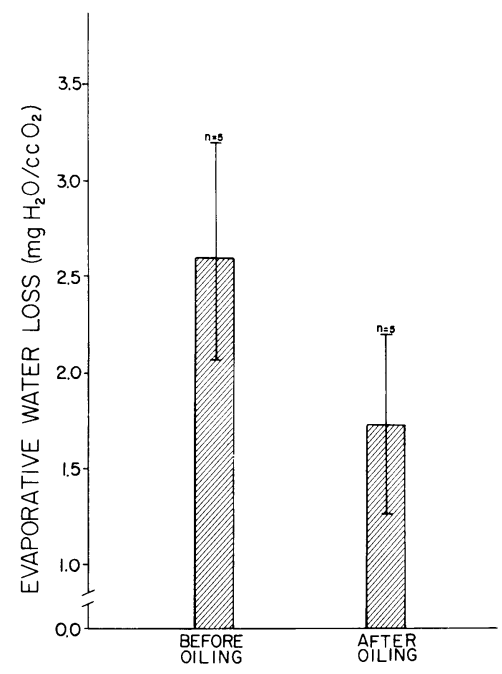

FIG. 5.--Mean evaporative water loss $\left(\mathrm{mg} / \mathrm{cm}^{3} . \mathrm{O}_{2}\right)$ of five muskrats at an ambient temperature of $36 \mathrm{C}$ before and after the fur was rubbed with mineral oil. Vertical bars represent \pm 2 SEM.

clude providing cushioning and immunological defenses for the eye (Cohn 1955; Albini et al. 1974), functioning as an extraretinal photoreceptor and nonpineal gland source of melatonin (Wetterberg, Geller, and Yuwiler 1970; Panke, Reiter, and Rollag 1979), as well as synthesizing and releasing pheromones which elicit various conspecific behaviors (Thiessen 1977). Recently, Thiessen and Kittrell (1980) found that removal of the Hardarian gland 
from the gerbil decreased the concentration of fur lipids and the effectiveness of fur in retarding heat loss in a cold environment. However, in an attempt to generalize this function to other rodents, they found that lipid contents of Hardarianectomized Syrian golden hamsters, Sprague Dawley rats, and DBA/2J mice were not significantly different from those of sham-operated groups, suggesting the lack of a thermoregulatory function in these species. The present study suggests that the Hardarian gland of the semiaquatic species, Ondotra zibethicus, does serve a thermoregulatory function for retarding water penetration into and away from the fur.

Johansen (1962) demonstrated that the muskrat's nonwettable fur retains an insulating layer of air at the body surface which allows the muskrat to remain warm when submerged in near-freezing water. Hart (1962) and Sherer and Wunder (1979), however, presented data suggesting that muskrats become hypothermic from 3 to $5 \mathrm{C}$ when exposed to cold water for prolonged periods. These observations were supported by field observations of a 2-3 C drop in body temperature of telemetered muskrats during 40-50-min excursions from their lodge during the winter (MacArthur 1979). In order to minimize the extent of hypothermia during a swimming excursion, the muskrat has been observed to increase its body temperature during the $60 \mathrm{~min}$ prior to leaving the lodge (MacArthur 1979). Not only does this result in hyperthermia prior to submergence, it may also be accompanied by a period of grooming and waterproofing of the fur.

In the gerbil, an increased body temperature provokes autogrooming and Hardarian gland secretion release from the external nares (Thiessen and Kittrel 1980). This secretion is mixed with saliva and is spread over the face and body. Similar behavior was observed on muskrats in the communal holding cages. Prior to leaving the feeding platform and entering the water, individual animals would spend 3040 min first rubbing their face, nose, and mouth with their paws, then rubbing their paws along the back of their head as well as the ventral and lateral sides of their body. Communal grooming commenced after the first muskrat began its auto- grooming, perhaps in response to pheromones released from the Hardarian gland (Thiessen 1977). This social activity was simple and consisted primarily of one muskrat rubbing its face and head along the back of conspecifics. Since muskrats generally live with several other individuals in a lodge during the winter (Schwartz and Schwartz 1959), communal grooming during the period of heat generation prior to entering the cold water could result in the full body spreading of lipids from Hardarian gland secretions.

Total removal of surface skin and fur lipids by shampooing dramatically reduced the muskrat's insulative ability and resulted in a significantly increased loss of body heat when submerged in cold water. Hardarian gland removal also resulted in a considerably larger reduction in body temperature than controls but not as great as total lipid removal. These results support the hypothesis that Hardarian gland secretions augment the thermoregulatory function of sebaceous gland lipid production in this semiaquatic mammal. It is possible that these lipids function by maintaining an air boundary between the skin and water. Support for this hypothesis is offered by a study in which all the air in the fur of muskrats was removed by rubbing the animal with a solution of the highly surface-active material "Aerosol OT" (diactyl-sodium sulfasiccinate). This treatment not only decreased the volume of muskrats' fur by about $21 \%$ but also appreciably reduced its heat-retaining capacity in cold water (Johansen 1962).

Removal of the Hardarian gland portion of fur lipids and consequent heat loss imply an associated increase in conductance of the fur. However, the calculated values for conductance were not significantly different between the Hardarianectomized and control groups. Indeed, both groups had conductance values very close to the predicted value based upon allometric equations (Herreid and Kessel 1967). It is possible that a difference in conductance of the fur between Hardarianectomized and control muskrats may be evident when the animals are submerged underwater as a result of lipid trapped air bubbles near the skin which increase the insulative property of the fur. The influence of fur lipids on 
conductance may not be evident when tested in cool air where the fur is piloerected rather than compressed. The thermal conductance of Hardarianectomized muskrats will soon be determined in water to test this hypothesis.

Mammalian skin is not completely impermeable to water and therefore accounts for a considerable proportion of total evaporative water loss. For example, Chew (1955) found that the deer mouse Peromyscus maniculatus sonoriensis had a cutaneous evaporative water loss that accounted for between $46 \%$ and $63 \%$ of the total evaporative water loss at $27 \mathrm{C}$. From calculations described in Material and methods, it was estimated that cutaneous water loss accounted for about $41 \%$ of the total evaporative water loss in muskrats, which was increased to $66 \%$ by shampooing and $52 \%$ by Hardarianectomy.

It is widely believed that the physical characteristics of the stratum corneum determine the rate of insensible water loss across the skin (Blank 1952; Mali 1956). However, as pointed out by Edwards and Haines (1978), an additional means by which cutaneous evaporative water loss could be increased would be a reduction of the effective boundary layer of air within and above the fur. These authors speculate that this would result in the steepening of the vapor pressure gradient between the evaporating surface and the ambient air. The importance of lipids in influencing the boundary layer and consequently retarding cutaneous water loss has not been adequately explored. Nicolaides suggested that the lipids that are secreted by the sebaceous glands may provide waxes, fatty acids, and alcohols that, when spread over the water at the skin surface, could form monolayers that might retard evaporation.
In addition, Quay (1965) noted that species of Dipodomys and some Perognathus have antero-posterior flattened hair shafts that form overlapping plates of hair fixed to one another by a lipid film. It is speculated that this may contribute to the prevention of cutaneous evaporative water loss. If, indeed, lipicss retard water loss from the fur, one would expect shampooed and, to a lesser extent, Hardarianectomized muskrats to have an increased evaporative water loss over controls. Lipid removal from the fur of muskrats by shampooing did appear to increase evaporative water loss per unit of oxygen consumed, suggesting an increase in cutaneous evaporation. Hardarian gland removal also resulted in an increased water loss per unit of oxygen consumption. In addition, covering the fur with oil diminished the evaporative water loss. In this latter case, however, it is possible that the oily fur decreased the palatability of licking and perhaps saliva spreading as a thermoregulatory behavior. If so, this would account for a portion of the reduced evaporative water loss.

Even though the muskrat is a semiaquatic mammal with little apparent problem with water deprivation, it does encounter periods of heat stress during which it remains in the lodge isolated from its aquatic environment (MacArthur and Aleksiuk 1979). However, the importance of fur lipids for this semiaquatic animal may be primarily for retarding water penetration and heat loss while in cold water. Impaired water loss under hot, dry conditions may be simply a secondary effect of the fur lipids forming an air layer next to the skin. This latter effect may be of greater adaptive benefit to those species living in a more xeric environment (Quay 1965; Thiessen and Kittrell 1980).

\section{LITERATURE CITED}

Albini. B., G. Wick, E. Rose, and E. Orlans 1974. Immunoglobin production in chicken Hardarian glands. Int. Arch. Allergy Appl. Immunol. 47:23-34.

BLANK, L. H. 1952. Factors which influence the water content of the stratum corneum. J. Invest. Dermatol. 18:433-440.

Chew, R. M. 1955. The skin and respiratory water losses of Peromyscus maniculatus sonoriensis. Ecology 36:463-467

CoHN, S. A. 1955. Histochemical observations of the
Hardarian gland of the albino mouse. J. Histochem. Cytochem. 3:342-353.

Davis, F. A. 1929. The anatomy and histology of the eye and orbit of the rabbit. Transcripts Amer. Ophthalmol. Soc. 27:401-441.

Depocas, F., and J. S. Hart. 1957. Use of the Pauling oxygen analyzer measurement of oxygen consumption in open-circuit systems and in short-lag closed-circuit apparatus. J. Appl. Physiol. 10:388393.

Edwards, R. M., and H. Haines. 1978. Effect of 
ambient water vapor pressure and temperature on evaporative water loss in Peromyscus maniculatus and Mus musculus. J. Comp. Physiol. 128: $177-184$.

Graffin, A. L. 1942. Histological observations upon porphyrin-excreting Hardarian gland of the albino rat. Amer. J. Anat. 71:43-64.

Hais, I. M., A. Strych, and V. Chemlar. 1968. Preliminary thin-layer chromatographic characterization of the rat Hardarian gland lipids. J. Chromatogr. 35:179-191.

HART, J. S. 1962. Temperature regulation and adaptation to cold climates. In J. P. HANNON and E. Viereck, eds. Comparative physiology of temperature regulation. Arctic Aeromedical Laboratory, Fort Wainwright, Alaska.

Herreid, C. F., and B. Kessel. 1967. Thermal conductance in birds and mammals. Comp. Biochem. Physiol. 21:405-414.

JoHANSEN, K. 1962. Buoyancy and insulation in the muskrat. J. Mammal. 43(1):64-68.

KenNEDY, G. Y. 1970. Harderoporphyrin: a new porphyrin from the Hardarian glands of the rat. Comp. Biochem. Physiol. 36:21-26.

LAy, D. W. 1945. Muskrat investigations in Texas. J. Wildlife Manage. 9:56-76.

MacArThur, R. A. 1979. Seasonal patterns of body temperature and activity in free-ranging muskrats (Ondotra zibethicus). Can J. Zool. 57:25-33.

MacArthur, R. A., and M. Aleksiuk. 1979. Seasonal microenvironments of the muskrat (Ondotra zibethicus) in a northern marsh. J. Mammal. 60(1): 146-154.

MALI, J. H. W. 1956. The transport of water through the human epidermis. J. Invest. Dermatol. 27:451469.

MilleR, K. L., and L. IRving. 1967. Temperaturerelated nerve function in warm and cold climate muskrats. Amer. J. Physiol. 213(5):1295-1298.

Netter, J., and W. Wasserman. 1974. Applied linear statistical models. Irwin, London.

Nicolaides, N. 1974. Skin lipids: their biochemical uniqueness. Science 184:19-22.

Panke, E. S., R. J. Reiter, and M. D. Rollag. 1979. Effect of removal of the Hardarian glands on pineal melatonin concentrations in the Syrian hamster. Experientia 35:1405-1406.

QUAY, W. B. 1965. Integumentary modifications of North American desert rodents. Pages 59-74 in A. B. Lyne and B. F. Short, eds. Biology of the skin and hair growth. Angus \& Robertson, Sydney.

Schwartz, C. W., and E. R. Schwartz. 1959. The wild mammals of Missouri. University of Missouri Press and Missouri Conservation Commission, Columbia.

Sherer, J., and B. A. Wunder. 1979. Thermoregulation of a semi-aquatic mammal, the muskrat, in air and water. Acta Theriologica 19:249-256.

SoKAL, R. R., and F. J. RohlF. 1969. Biometry: the principles and practices of statistics in biological research. W. H. Freeman, San Francisco.

Thiessen, D. D. 1977. Progress in physiology and physiological psychology. Vol. 7. Academic Press, New York.

Thiessen, D. D., and N. W. Kittrell. 1980. The Hardarian gland and thermoregulation in the gerbil(Merionesunguiculatus). Physiol. Behav. 24:417424.

Venable, J. H., and A. L. Grafflin. 1970. Gross anatomy of the orbital gland in the albino rat. J. Mammal. 21:66-71.

Wetterberg, L., E. Geller, and A. Yuwiler. 1970. Hardarian gland: an extraretinal photoreceptor influencing the pineal gland in neonatal rats? Science 167:884-885. 